\title{
$\beta$-lapachone suppresses the proliferation of human malignant melanoma cells by targeting specificity protein 1
}

\author{
WOONG BANG $^{1 *}$, YOUNG-JOO JEON ${ }^{1 *}$, JIN HYOUNG CHO $^{1 *}$, RA HAM LEE $^{1}$, SEON-MIN PARK $^{2}$, \\ JAE-CHEON SHIN ${ }^{2}$, NAG-JIN CHOI ${ }^{3}$, YUNG HYUN CHOI ${ }^{4}$, JUNG-JAE CHO ${ }^{5}$, JAE-MIN SEO ${ }^{6}$, \\ SEUNG-YEOP LEE ${ }^{7}$, JUNG-HYUN SHIM ${ }^{5}$ and JUNG-IL CHAE ${ }^{1}$
}

\begin{abstract}
${ }^{1}$ Department of Dental Pharmacology, School of Dentistry and Institute of Oral Bioscience, BK21 Plus, Chonbuk National University, Jeonju 561-756; ${ }^{2}$ Pohang Center for Evaluation of Biomaterials, Pohang, Gyeongbuk 790-834; ${ }^{3}$ Department of Animal Science, College of Agricultural and Life Science, Chonbuk National University, Jeonju 561-756; ${ }^{4}$ Department of Biochemistry, Dongeui University College of Oriental Medicine, Busan 614-052; ${ }^{5}$ Department of Pharmacy, College of Pharmacy and Natural Medicine Research Institute, Mokpo National University, Jeonnam 534-729;

${ }^{6}$ Department of Prosthodontics, School of Dentistry and Institute of Oral Bio-Science and Research Institute of Clinical Medicine, Chonbuk National University, Jeonju 561-756; ${ }^{7}$ Cluster for Craniofacial Development and Regeneration Research, Institute of Oral Biosciences and School of Dentistry, Chonbuk National University, Jeonju 561-756, Republic of Korea
\end{abstract}

Received August 21, 2015; Accepted October 6, 2015

DOI: $10.3892 /$ or.2015.4439

\begin{abstract}
. $\beta$-lapachone ( $\beta$-lap), a novel natural quinone derived from the bark of the Pink trumpet tree (Tabebuia avellanedae) has been demonstrated to have anticancer activity. In this study, we investigated whether $\beta$-lap exhibits anti-proliferative effects on two human malignant melanoma (HMM) cell lines, G361 and SK-MEL-28. The effects of $\beta$-lap on the HMM cell lines were investigated using 3-(4,5-dimethylthiazol-2-yl)-5-(3-carb oxymethoxyphenyl)-2-(4-sulfophenyl-2H-tetrazolium (MTS) assay, 4',6-diamidino-2-phenylindole (DAPI) staining, Annexin V and Dead cell assay, mitochondrial membrane potential (MMP) assay and western blot analysis. We demonstrated that $\beta$-lap significantly induced apoptosis and suppressed cell viability in the HMM cells. Intriguingly, the transcription factor specificity protein $1(\mathrm{Sp} 1)$ was significantly downregulated by $\beta$-lap in a dose- and time-dependent manner. Furthermore, $\beta$-lap modulated the protein expression level of the Sp1 regulatory genes including cell cycle regulatory
\end{abstract}

Correspondence to: Professor Jung-Hyun Shim, Department of Pharmacy, College of Pharmacy, Mokpo National University, 1666 Youngsan-ro, Muan-gun, Jeonnam 534-729, Republic of Korea E-mail: s1004jh@gmail.com

Professor Jung-Il Chae, Department of Dental Pharmacology, School of Dentistry, BK21 Plus, Chonbuk National University, Jeonju 561-756, Republic of Korea

E-mail: jichae@jbnu.ac.kr

*Contributed equally

Key words: $\beta$-lapachone, HMM, Sp1, apoptosis proteins and apoptosis-associated proteins. Taken together, our findings indicated that $\beta$-lap modulates Sp1 transactivation and induces apoptotic cell death through the regulation of cell cycle- and apoptosis-associated proteins. Thus, $\beta$-lap may be used as a promising anticancer drug for cancer prevention and may improve the clinical outcome of patients with cancer.

\section{Introduction}

Human malignant melanoma (HMM), the most deadly form of skin cancer, is found in the outer layer of the skin and is responsible for $\sim 60 \%$ of lethal skin tumors (1). HMM incidence and mortality have steadily increased over the last 50 years in the fair-skinned population (2). The most common risk factors for the development of HMM include exposure to ultraviolet radiation (especially in childhood), fair skin, dysplastic nevi syndrome, age and family history (3). Current treatment modalities for HMM, including surgery, radiation and chemotherapy, are not efficient enough to prevent the spread of metastases in up to $50 \%$ of patients (4). For patients with stage IV disease, the melanoma has spread beyond the local area into other parts of the body or internal organs. Although surgery and radiation therapy are the main treatment for malignant melanoma, systemic therapy such as cytotoxic chemotherapy and immunotherapy is the mainstay of treatment for most patients with stage IV melanoma (5). Therefore, there is an ongoing quest for novel effective chemotherapeutic agents for HMM. One of the recently suggested agents for the treatment of cancer is $\beta$-lapachone ( $\beta$-lap).

$\beta$-lap (3.4-dihydro-2,2-dimethyl-2H-naphthol[1,2-b]pyran5,6 -dione) is a natural quinone derived from the bark of the Pink trumpet tree (Tabebuia avellanedae), which has been used in traditional medicine for centuries (6). Previous studies have reported that $\beta$-lap has anti-bacterial (7), anti-fungal (7), 
anti-inflammatory (8), anti-viral (9), anti-proliferative $(10,11)$, anti-psoriasis (12), and anti-arthritic properties (13). In addition, $\beta$-lap was also reported to sensitize cancer cells to ionizing radiation (14), DNA damaging agents (15) and increase the generation of reactive oxygen species (16). In particular, the anti-proliferative effect of $\beta$-lap on various cancer cell lines including prostate cancer $(10,11,17)$, breast cancer $(18,19)$, lung cancer (20) and gastric carcinoma (21) has been reported.

Specificity protein 1 , a member of the specificity protein/Kruppel-like factor family of transcription factors, is responsible for a variety of cellular processes (22). Previous studies have reported that $\mathrm{Sp} 1$ is related to tumorigenesis by modulating transcription associated with cell growth and proliferation (23). Furthermore, Sp1 is highly expressed in various cancer cell lines compared to normal cells. In this regard, a decrease in cancer proliferation was found to occur following inhibition of Sp1 by small interfering RNA in nude mice (15,24-26). Hence, many studies have revealed that regulation of the function by $\mathrm{Sp} 1$ is a promising therapeutic target in cancer (27).

Although the anti-proliferative properties of $\beta$-lap against several cancer cell lines have been demonstrated, its effect on HMM and the mechanisms of $\beta$-lap-induced apoptosis are not yet fully understood. In this study, we examined the effect of $\beta$-lap on two HMM cell lines, G361 and SK-MEL-28. We determined that $\beta$-lap inhibited cell viability and induced apoptosis in the G361 and SK-MEL-28 cells. The results from the present study provide experimental evidence to support the hypothesis that $\beta$-lap decreases $\mathrm{Sp} 1$ expression and inhibits HMM cell viability by inducing cell cycle arrest and apoptosis. Our results reinforce the potential pharmacological interest of $\beta$-lap, as confirmed by the suppression of Sp1 in HMM cells.

\section{Materials and methods}

Cell culture. Human malignant melanoma (HMM) cell lines, G361 and SK-MEL-28, were cultured in Hyclone Dulbecco's modified Eagle's medium (DMEM; Welgene, Dea-gu, Korea) with $10 \%$ fetal bovine serum (FBS) and $100 \mathrm{U} / \mathrm{ml}$ each of penicillin and streptomycin (Gibco, Grand Island, NY, USA) at $37^{\circ} \mathrm{C}$ with $5 \% \mathrm{CO}_{2}$ in a humidified atmosphere.

Cell viability assay. Viability of the G361 and SK-MEL-28 cells treated with $\beta$-lap was measured using the CellTiter96 ${ }^{\circledR}$ Aqueous One cell proliferation assay kit (Promega, Madison, WI, USA) according to the manufacturer's instructions. The effect of $\beta$-lap on the viability of the G361 and SK-MEL-28 cells was estimated by 3-(4,5-dimethylthiazol-2-yl)-5-(3-carboxymethoxyphenyl)-2-(4-sulfophenyl)-2H-tetrazolium (MTS) assay. G361 $\left(3 \times 10^{3}\right)$ and SK-MEL-28 $\left(3 \times 10^{3}\right)$ cells were seeded into 96 -well plates and were treated with various concentrations of $\beta$-lap for 24 and $48 \mathrm{~h}$. MTS reagent was added directly to the cells and incubated at $37^{\circ} \mathrm{C}$. Absorbance was measured using an absorbance microplate reader (Biotek, Winooski, VT, USA) at $490 \mathrm{~nm}$. All experiments were carried out in triplicates, and the percentage of cell viability of the $\beta$-lap-treated cells was normalized to that of the untreated control cells.

DAPI staining. Chromatin condensation and nuclear fragmentation in apoptotic cells were assessed by 4',6-diamidino-2-phenylindole (DAPI) staining. G361 and SK-MEL-28 cells were treated with various concentrations of $\beta$-lap for $48 \mathrm{~h}$ and then harvested by trypsinization. The detached cells were fixed in $100 \%$ methanol at room temperature for $30 \mathrm{~min}$, deposited on slides, and stained with DAPI (Sigma-Aldrich, St. Louis, MO, USA) solution ( $2 \mu \mathrm{g} / \mathrm{ml})$. Cell morphology was observed under a FluoView confocal laser microscope (Fluoview FV10i; Olympus Corporation, Tokyo, Japan).

Annexin V and Dead Cell assay. Annexin V and Dead Cell assay was performed using Muse ${ }^{\mathrm{TM}}$ Cell Analyzer from Millipore (Billerica, MA, USA) following the manufacturer's instructions. Briefly, after treatment with the various concentrations of $\beta$-lap, the G361 and SK-MEL-28 cells were incubated with Annexin V and Dead cell reagent (7-ADD) and the events for dead, late apoptotic, early apoptotic, and live cells were counted.

Mitochondrial membrane potential (MMP) assay. MMP was determined with 5,5',6,6'-tetrachloro-1,1',3,3'-tetraethyl-benzimidazolyl-carbocyanine iodine (JC-1) by using the Muse ${ }^{\mathrm{TM}}$ Cell Analyzer from Millipore following the manufacturer's instructions. The samples were analyzed by flow cytometry and counted (10,000 cells/sample). Loss of MMP was quantified as the percentage of cells expressing JC-1 monomer fluorescence.

Western blot analysis. G361 and SK-MEL-28 cells were treated with $\beta$-lap, and then the cells were washed twice with ice-cold PBS. Whole cell lysate was prepared using M-PER ${ }^{\circledR}$ Mammalian Protein Extraction reagent (Thermo Scientific, Rockford, IL, USA) containing a protease inhibitor cocktail (Roche, Switzerland). Protein concentrations were estimated using the BCA protein assay kit (Thermo Scientific). The samples were separated by 8 or $12 \%$ SDS-polyacrylamide gel electrophoresis, and were then transferred to polyvinylidene difluoride (PVDF) membranes (Millipore). The membranes were blocked with $5 \%$ (v/v) skim milk in TBS buffer containing $0.1 \%$ Tween-20 and then incubated with the primary antibody overnight at $4^{\circ} \mathrm{C}$. Subsequently, the membranes were washed 5 times in TBS buffer including $0.1 \%$ Tween-20 for $10 \mathrm{~min}$ and incubated with horseradish peroxidase-conjugated anti-mouse, anti-rabbit or anti-goat $\mathrm{IgG}$ antibodies. The membranes were visualized using a chemiluminescent ECL detection kit (Thermo Scientific) and detected using ImageQuant Las 4000 Mini (GE Healthcare Life Sciences) according to the manufacturer's instructions.

Statistical analysis. Data are reported as the means \pm SD of triplicate independent experiment. Statistical significance was assessed using the Student's t-test. A value of $\mathrm{P}<0.05$ compared with the untreated control was considered to be statistically significant.

\section{Results}

$\beta$-lap inhibits the cell viability of HMM cells. Previous studies have reported that $\beta$-lap has anti-proliferative effects on several different cancer cells $(10,11)$. The structure of $\beta$-lap is 
A

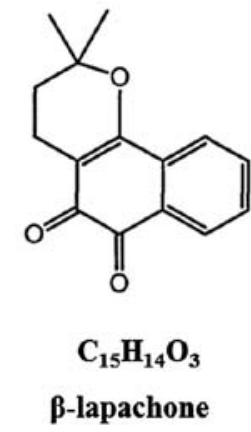

B

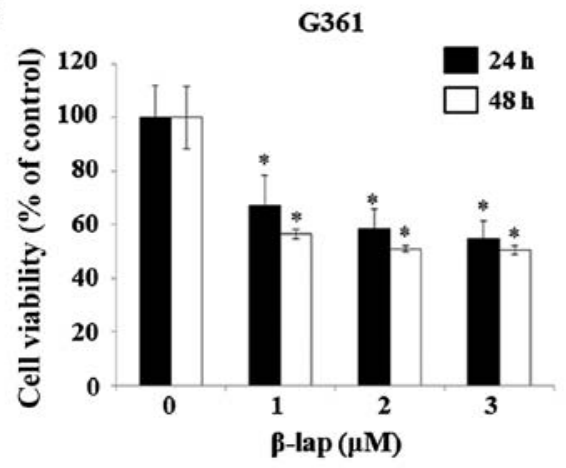

SK-MEL-28

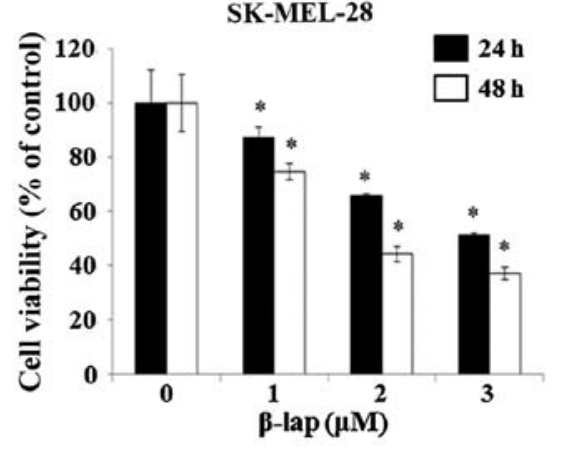

C

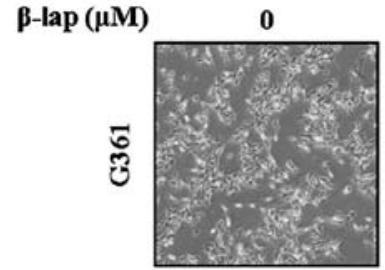

$\beta$-lap $(\mu \mathrm{M})$

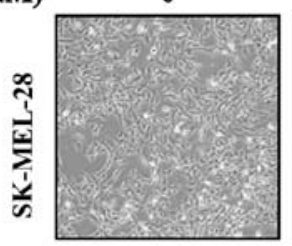

1

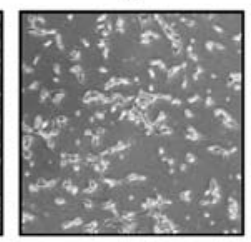

1

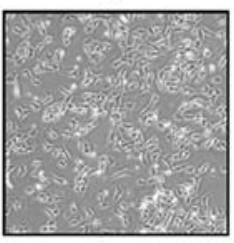

2

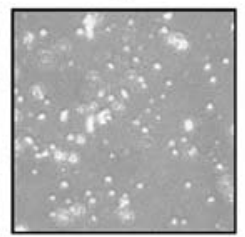

2

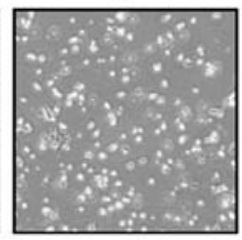

3

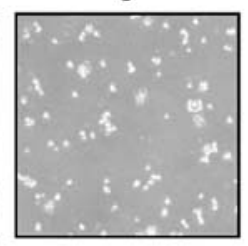

3

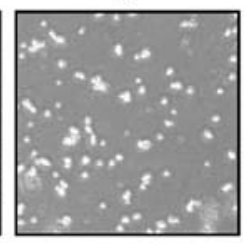

Figure 1. Effect of $\beta$-lapachone ( $\beta$-lap) on the cell viability of the HMM cells. (A) Chemical structure of $\beta$-lap. (B) Effect of $\beta$-lap on the cell viability of G361

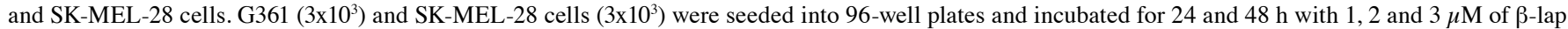
or without in DMEM. The cell viability was measured by MTS assay as described in Materials and methods. The results are expressed as the means \pm SD. $(n=3)$. (C) Morphological changes including an increase in rounded cell and a decrease in the whole cell number were noted in the G361 and SK-MEL-28 cells treated with $0,1,2$ and $3 \mu \mathrm{M}$ of $\beta$-lap for $48 \mathrm{~h}$.

shown in Fig. 1A. To investigate the effect of $\beta$-lap on G361 and SK-MEL-28 cells, cell viability was measured using MTS assay. The cell viability of G361 was $56.5 \pm 0.02,50.9 \pm 0.01$ and $50.5 \pm 0.01$ following treatment with 1,2 and $3 \mu \mathrm{M}$ of $\beta$-lap, respectively, compared with the untreated control cells at $48 \mathrm{~h}$ post-treatment. In the case of SK-MEL-28 cells, cell viability was $74.5 \pm 0.03,44.1 \pm 0.03$ and $37.0 \pm 0.02$ following treatment with 1,2 and $3 \mu \mathrm{M}$ of $\beta$-lap for $48 \mathrm{~h}$, respectively, compared to that of the untreated control cells at $48 \mathrm{~h}$ post-treatment. The results indicated that $\beta$-lap decreased the viability of G361 and SK-MEL-28 cells in a dose- and time-dependent manner (Fig. 1B). Following, the morphological alterations of the G361 and SK-MEL-28 cells were observed using an optical microscope following treatment with $\beta$-lap (1-3 $\mu \mathrm{M})$ for $48 \mathrm{~h}$. As shown Fig. 1C, the numbers of irregular and rounded cells were increased by $\beta$-lap $(0,1,2$ and $3 \mu \mathrm{M})$. Thus, these results determined that $\beta$-lap inhibited the cell viability of the HMM cells.

$\beta$-lap induces apoptosis in HMM cells. In order to investigate apoptotic morphological alterations in the G361 and SK-MEL-28 cells, they were treated with $\beta$-lap at various concentrations $(0,1,2$ and $3 \mu \mathrm{M})$. The cells were stained with DAPI and then observed under a FluoView confocal laser microscope. As shown in Fig. 2A, the percentage of cells with nuclear condensation and perinuclear apoptotic bodies was increased in a $\beta$-lap dose-dependent manner in the HMM cells.

We confirmed that apoptosis was mainly induced upon exposure to $\beta$-lap by the Annexin V and Dead Cell assay and MMP assay in the G361 and SK-MEL-28 cells. The upper right quadrant and the lower right quadrant, respectively, indicated late and early apoptotic cells and the percentage of these apoptotic cells was increased by $\beta$-lap $(1,2$ and $3 \mu \mathrm{M})$ when compared to the cells without treatment (Fig. 2B). The lower left quadrant indicated depolarized cells and the percentage of these cells was increased by $\beta$-lap $(0,1,2$ and $3 \mu \mathrm{M})$ (Fig. $2 \mathrm{C}$ ). These results indicated that $\beta$-lap treatment effectively inhibited cell proliferation, leading to apoptosis in the HMM cells.

Expression of Spl is suppressed by $\beta$-lap in HMM cells. Sp1 is overexpressed in various human cancers, including human glioblastoma (28), lung cancer (24) and pancreatic cancer (29), and is regulated by chemotherapeutic agents (30) and natural compounds, including honokiol and esculetin (27,31). Thus, we investigated whether the expression level of Sp1 was regulated by $\beta$-lap in the HMM G361 and SK-MEL-28 cells. We determined whether the expression level of Sp1 was altered by $\beta$-lap in the G361 and SK-MEL-28 cells. We detected Sp1 expression levels by western blot analysis. The expression levels were significantly reduced in the treated cells, with a 
$\mathbf{A}$

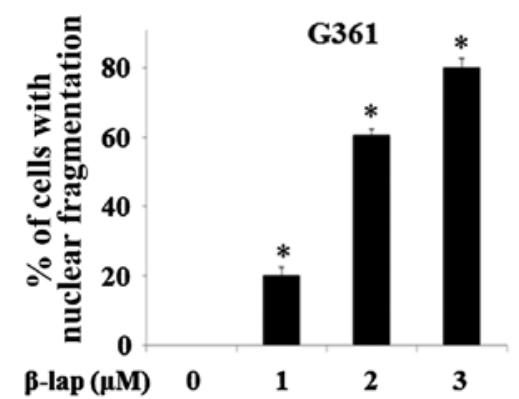

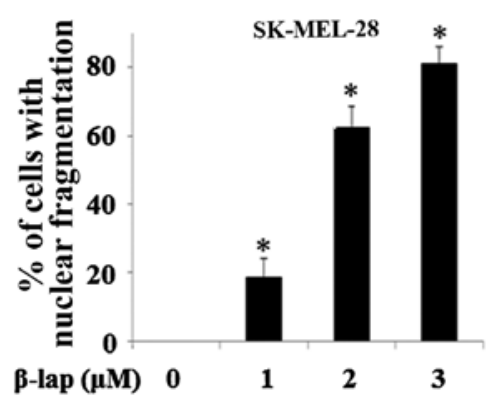
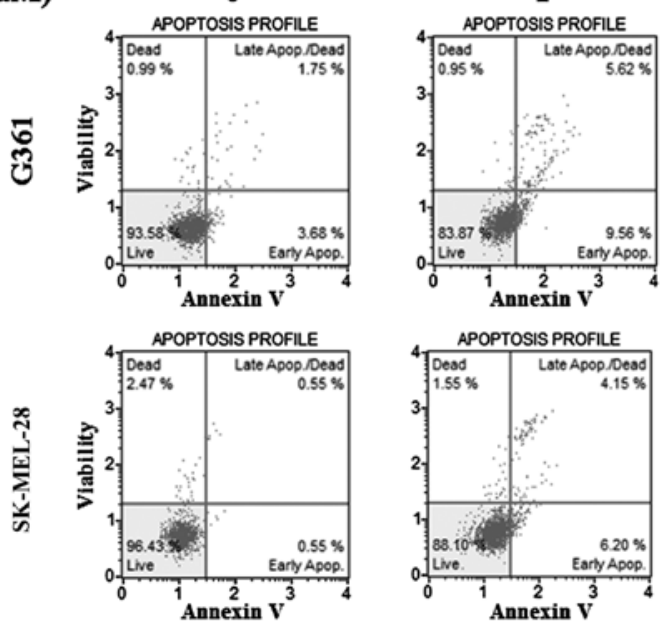

C

\section{B-lap $(\mu \mathrm{M})$}
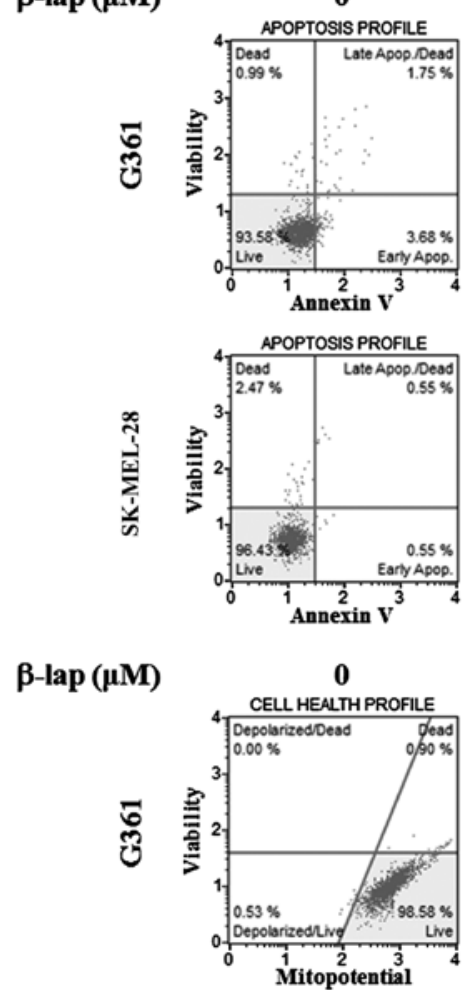

CELL HEALTH PROFILE

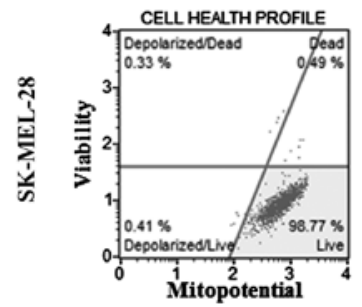

1

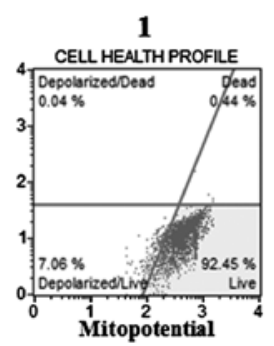

CELL HEALTH PROFILE

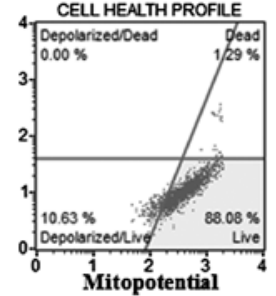

2
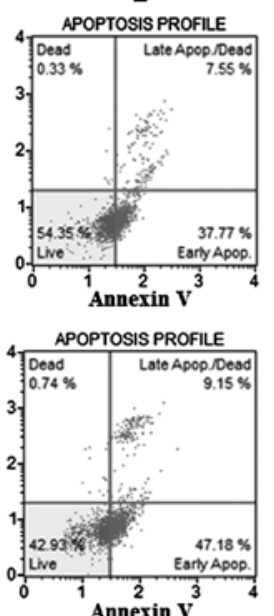

2
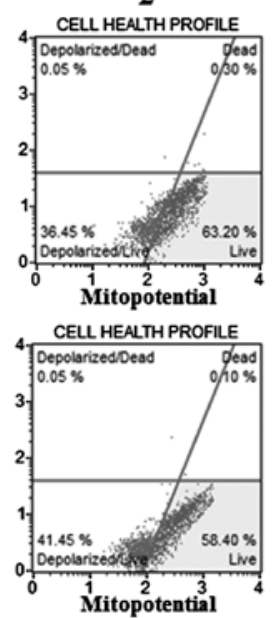
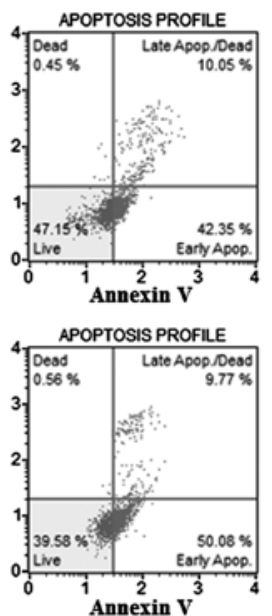

3

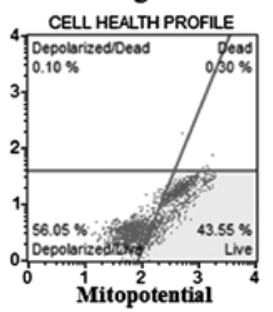

CELL HEALTH PROFILE

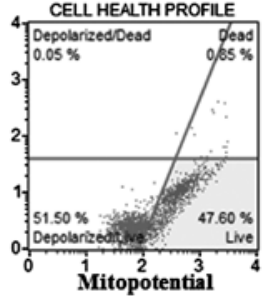

Figure 2. Apoptotic effect induced by $\beta$-lapachone ( $\beta$-lap) in the HMM cells. Cells were incubated with $\beta$-lap ( $0,1,2$ and $3 \mu$ M) for 48 h. (A) Treated or untreated cells were stained with DAPI, and the cells with DNA fragmentation and chromatin condensation were quantified. Data are shown as the mean \pm SD $(n=3)$. A significant difference compared to the untreated control cells, * $P<0.05$. (B) Dot graphs of the Annexin V and Dead Cell assay. Annexin V indicates apoptotic cells and Dead cell assay is indicative of cell necrosis. The cells treated with $\beta$-lap were assessed using the Annexin V and Dead cell assay, as described in Materials and methods. The upper right quadrant indicates late apoptotic cells and the lower right quadrant indicates early apoptotic cells (C) Mitochondrial membrane potential as measured by JC-1 staining. JC-1 staining is indicative of the disruption of mitochondrial membrane potential and the lower left quadrant indicates depolarized cells.

maximum decrease of $62.4 \pm 0.01 \%$ in the G361 cells compared to the untreated cells and a maximum decrease of $61.6 \pm 0.01 \%$ was noted in the SK-MEL-28 cells compared to the untreated group (Fig. 3A and B). To further determine the apoptotic effect by the downregulation of Sp1 in the cells treated with $\beta$-lap, we treated the G361 and SK-MEL-28 cells with $3 \mu \mathrm{M} \beta$-lap for different times $(0,12,24$ and $48 \mathrm{~h})$ and investigated the expression levels of PARP and cleaved PARP (Fig. 3C and D). Thus, these results demonstrated that $\beta$-lap induces apoptosis through downregulation of Sp1.

$\beta$-lap regulates cell cycle arrest and apoptosis in the HMM cells. To investigate the regulatory effect of $\beta$-lap, we examined the changes in expression levels of Sp1 downstream 
A

G361
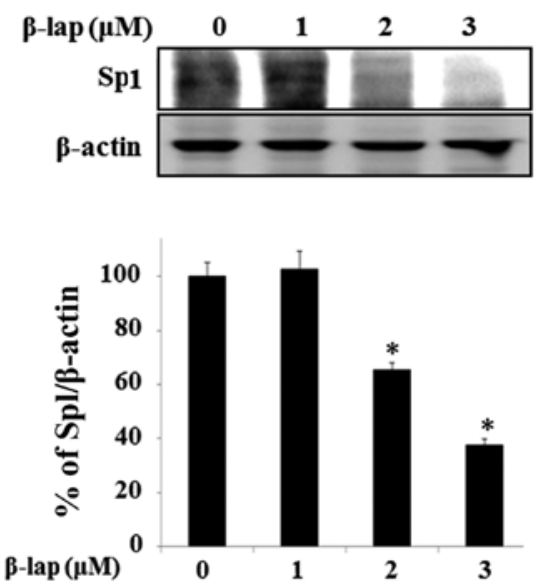

C

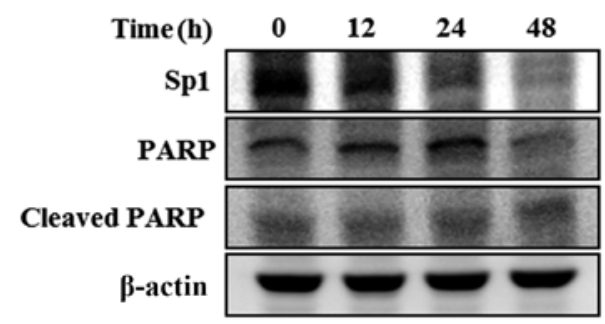

B

SK-MEL-28
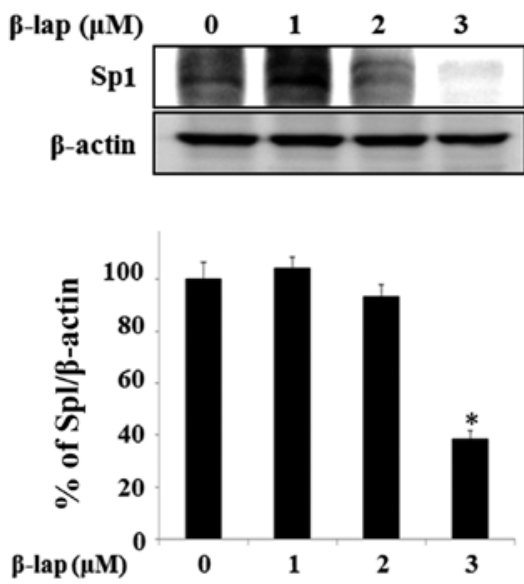

D

SK-MEL-28

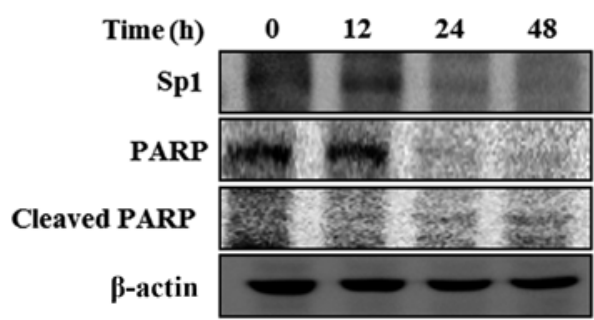

Figure 3. Effect of $\beta$-lapachone ( $\beta$-lap) on specificity protein 1 (Sp1) protein expression in the HMM cells. (A) G361 and (B) SK-MEL-28 cells were treated with different concentrations of $\beta$-lap $(0,1,2$ and $3 \mu \mathrm{M})$ for $48 \mathrm{~h}$. The cell lysates were separated by SDS-PAGE and then transferred from SDS-PAGE gels to membranes and subjected to western blot analysis for Sp1. Equal loading protein was confirmed using $\beta$-actin. The histogram shows the ratio of Sp1 to actin expression, and the results are expressed as the average of triplicate samples from three independent experiments. ${ }^{*} \mathrm{P}<0.05$ vs. the untreated control cells. (C) G361 and (D) SK-MEL-28 cells were treated with $3 \mu \mathrm{M} \beta$-lap for 0, 12, 24 and $48 \mathrm{~h}$ and then expression levels of Sp1, PARP and cleaved PARP were detected. Equal loading protein was confirmed using $\beta$-actin.

A

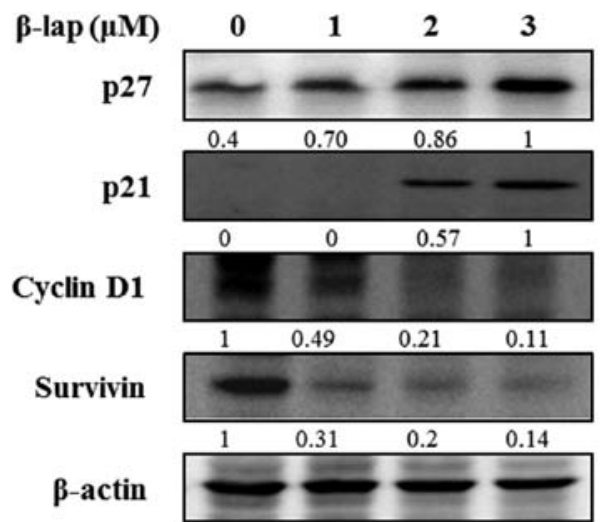

B

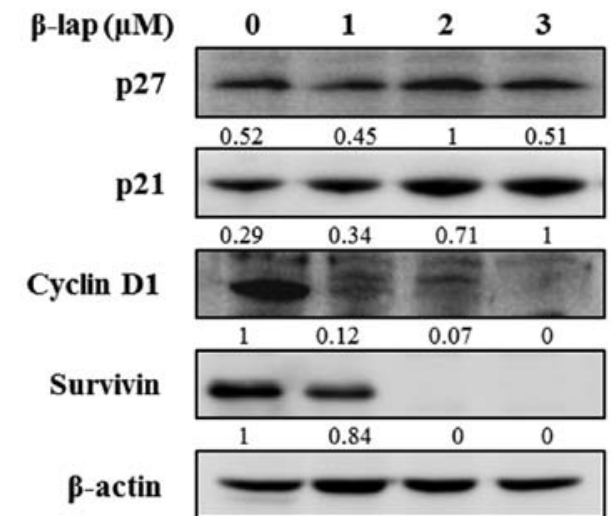

Figure 4. Effect of $\beta$-lapachone ( $\beta$-lap) on downstream target proteins of specificity protein 1 (Sp1). (A) G361 and (B) SK-MEL-28 cells were incubated with $\beta$-lap $(1,2$ and $3 \mu \mathrm{M})$ or without for $48 \mathrm{~h}$. The cell lysates were lysed and then the samples were subjected to western blot analysis using antibodies against p27, p21, cyclin D1 and survivin. Equal loading protein was confirmed using $\beta$-actin. The values were measured by ImageJ densitometry (NIH, USA) and the data are expressed as a representative of two or three independent experiments.

targets and apoptosis-related proteins. The cell cycle arrest proteins, including $\mathrm{p} 27$ and p21, were significantly increased following treatment with different concentrations of $\beta$-lap, whereas cell proliferation and survival-related proteins, cyclin D1 and survivin, were decreased by $\beta$-lap in a concentration-dependent manner (Fig. 4). In addition, we assessed the expression levels of several pro- and anti-apoptotic proteins in the $\beta$-lap-treated G361 and SK-MEL-28 cells. As shown 
A G361

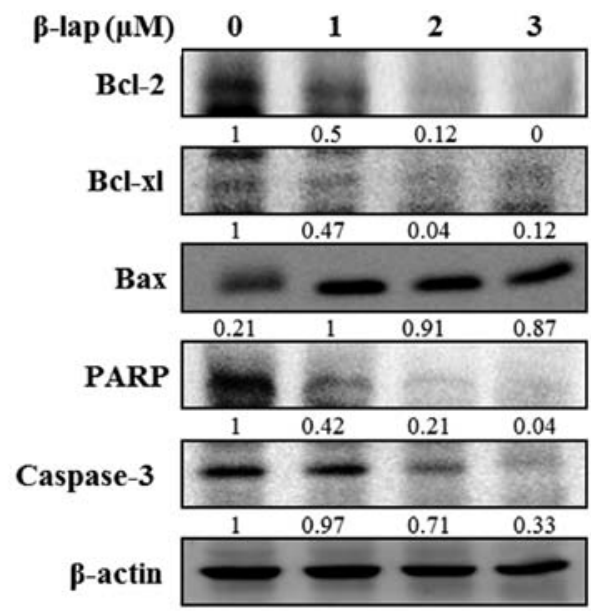

B

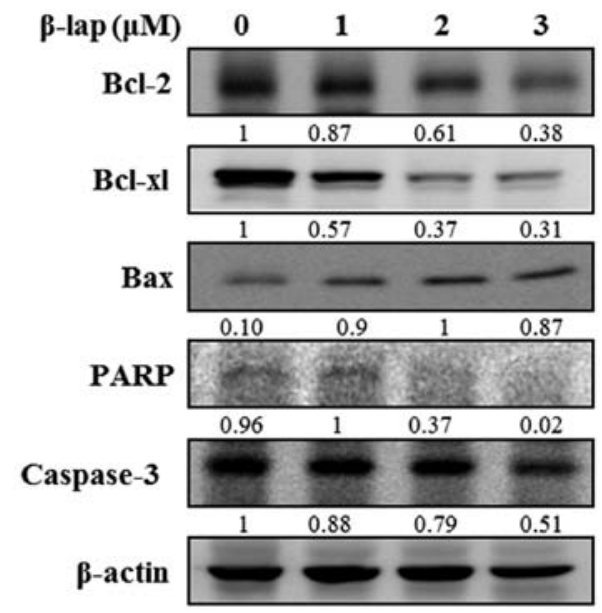

Figure 5. Effect of $\beta$-lapachone ( $\beta$-lap) on the apoptosis of HMM cells. (A) G361 and (B) SK-MEL-28 cells were treated with $\beta$-lap $(0,1,2$ and $3 \mu \mathrm{M})$ for $48 \mathrm{~h}$. The cell lysates were lysed and then the samples were subjected to western blot analysis using antibodies against Bcl-2, Bcl-xl, Bax, PARP and caspase-3. Equal loading protein was confirmed using $\beta$-actin. The values were measured by ImageJ densitometry (NIH, USA) and the data are representative of two or three independent experiments.

in Fig. 5, $\beta$-lap reduced the expression of Bcl-2 and Bcl-xl, and increased the expression of Bax to induce apoptotic cell death. $\beta$-lap also concentration-dependently caused activation of caspase-3 and PARP in the HMM cells. Our results showed that $\beta$-lap induced the downregulation of Sp1, resulting in cell cycle arrest and induction of apoptosis in the HMM cells.

\section{Discussion}

HMM is one of the most deadly types of skin cancer and its incidence has increased over the last 50 years in the fair-skinned population (2). Surgery, thermotherapy, chemotherapy and radiotherapy are used to treat HMM although these methods cause side effects, such as cytotoxicity to normal cells and host immune reaction (32). Hence, the objective of studies has concentrated upon natural compounds derived or originating from Mother Nature (33). Moreover, the value of natural compounds with anti-proliferative properties has been considered to play an important role in cancer therapy. In the present study, we concentrated on the anti-proliferative effect of $\beta$-lap, a novel natural quinone derived from the bark of the Pink trumpet tree (Tabebuia avellanedae) (34). $\beta$-lap has been reported as being a topoisomerase I and II inhibitor $(35,36)$, and was found to inhibit lymphocyte- (37), neutrophil- (37) and macrophage-related joint inflammatory (37). Thus, $\beta$-lap may be a potential agent against anti-proliferation. In this regard, several studies have reported that $\beta$-lap has an anti-proliferation effect on various cancer-derived cells, including breast carcinoma $(18,19)$ prostate carcinoma $(10,11,17)$, lung carcinoma (20) and gastric carcinoma (21). Despite numerous studies on cancer cells, the anti-proliferative properties of $\beta$-lap on HMM cells are not well understood.

In the present study, we demonstrated that $\beta$-lap induced apoptosis in HMM G361 and SK-MEL-28 cells. The apoptosis was accompanied by morphological alterations, such as chromatin condensation and rounded cells. We observed an increase in nuclear condensation and perinuclear apoptotic bodies though DAPI staining, and determined changes in the percentages of apoptotic and depolarized cells by Annexin V and Dead Cell assay and MMP assay following $\beta$-lap treatment. These results suggest that $\beta$-lap induces apoptosis in HMM cells.

The transcription factor, $\mathrm{Sp} 1$, is responsible for a variety of cellular processes, including transcription initiation, survival, cell growth, differentiation, metabolism and angiogenesis $(38,39)$. Previous studies have reported that $\mathrm{Sp} 1$ is overexpressed in cancer cells and contributes to the formation of cancer (40) as well as regulates cell cycle- and apoptosis-associated proteins $(25,41,42)$. In addition, several studies have shown that inhibition of Sp1 plays a role in growth inhibition and induction of apoptosis in malignant pleural mesothelioma and that Sp1 is activated in melanoma cells $(43,44)$. For these reasons, the regulation of Sp1 has been suggested to enhance the efficacy of cancer therapy and improve poor prognosis. Our data showed that the expression level of Sp1 was significantly deceased in the $\beta$-lap-treated HMM cells.

p21 and p27 are well known as negative regulators of cell cycle progression (45). The functions of p21 and p27 are responsible for sub-G1 phase arrest by interaction between cyclins and cyclin-dependent kinase (CDK) complexes $(46,47)$. Cyclin D1 performs functions, including proto-oncogene (48), tumorigenesis (49), cell maintenance (49) and integrator of extracellular signals of cells in early to mid-G1 phase (50). Survivin, an inhibitor of apoptosis (IAP) (51), plays an important role in mitosis and cell cycle arrest and apoptosis (52) and is also associated with Sp1-related oncogenes (53). The apoptotic caspases appear to be activated in a protease cascade and activated apical caspases respond to apoptotic stimuli and directly activate the effector caspases in a precisely controlled process (54). Among these caspases, caspase-3 plays a central 
role in the execution phase of both the intrinsic and extrinsic pathways of apoptosis by cleaving key cellular proteins, such as PARP (55). These cleavages regulate disassembly of the cell into the typical apoptotic morphological alterations, including cell shrinkage, chromatin condensation and DNA fragmentation (56). PARP is activated by binding DNA strand breaks produced by various DNA damaging agents, including hydrogen peroxide (57). Bcl-2 and Bcl-xl, blockers of cell death, are anti-apoptotic proteins and Bax, which promotes cell death, is a pro-apoptotic protein $(58,59)$. The results showed that $\beta$-lap-induced apoptosis was accompanied by the upregulation of p27, p21 and Bax and downregulation of cyclin D1, survivin, Bcl2, Bcl-xl, PARP and caspase-3, strongly suggesting that $\beta$-lap is a potential apoptosis-inducing agent by regulating $\mathrm{Sp} 1$ protein to exert anti-proliferation activity in HMM cells.

In the present study, we investigated the anti-proliferative effect of $\beta$-lap on HMM cells. The results of our study showed that $\beta$-lap inhibited cell growth and induced apoptosis through regulation of anti- and pro-apoptotic proteins by Sp1. Therefore, these results suggest that the anti-proliferative and apoptotic effects of $\beta$-lap are modulated by the regulation of Sp1-mediated gene products.

\section{Acknowledgements}

This study was supported by the Next-Generation BioGreen 21 Program (PJ01116401), Rural Development Administration, Republic of Korea.

\section{References}

1. Bandarchi B, Ma L, Navab R, Seth A and Rasty G: From melanocyte to metastatic malignant melanoma. Dermatol Res Pract 2010: pii: 583748, 2010.

2. Ferlay J, Steliarova-Foucher E, Lortet-Tieulent J, Rosso S, Coebergh JW, Comber H,Forman D and Bray F: Cancer incidence and mortality patterns in Europe: Estimates for 40 countries in 2012. Eur J Cancer 49: 1374-1403, 2013.

3. Erdmann F, Lortet-Tieulent J, Schüz J, Zeeb H, Greinert R, Breitbart EW and Bray F: International trends in the incidence of malignant melanoma 1953-2008 - are recent generations at higher or lower risk? Int J Cancer 132: 385-400, 2013.

4. Kesmodel SB and Spitz FR: Gene therapy for cancer and metastatic disease. Expert Rev Mol Med 5: 1-18, 2003.

5. Bhatia S, Tykodi SS and Thompson JA: Treatment of metastatic melanoma: An overview. Oncology (Williston Park) 23: 488-496, 2009.

6. Moon DO, Kang CH, Kim MO, Jeon YJ, Lee JD, Choi YH and Kim GY: Beta-lapachone (LAPA) decreases cell viability and telomerase activity in leukemia cells: Suppression of telomerase activity by LAPA. J Med Food 13: 481-488, 2010.

7. Guiraud P, Steiman R, Campos-Takaki GM, Seigle-Murandi F and Simeon de Buochberg M: Comparison of antibacterial and antifungal activities of lapachol and beta-lapachone. Planta Med 60: 373-374, 1994.

8. de Almeida ER, da Silva Filho AA, dos Santos ER and Lopes CA: Antiinflammatory action of lapachol. J Ethnopharmacol 29: 239-241, 1990.

9. Li CJ, Zhang LJ, Dezube BJ, Crumpacker CS and Pardee AB: Three inhibitors of type 1 human immunodeficiency virus long terminal repeat-directed gene expression and virus replication. Proc Natl Acad Sci USA 90: 1839-1842, 1993.

10. Planchon SM, Wuerzberger S, Frydman B, Witiak DT, Hutson P, Church DR, Wilding G and Boothman DA: Beta-lapachone-mediated apoptosis in human promyelocytic leukemia (HL-60) and human prostate cancer cells: A p53-independent response. Cancer Res 55: 3706-3711, 1995.
11. Planchon SM, Pink JJ, Tagliarino C, Bornmann WG, Varnes ME and Boothman DA: Beta-lapachone-induced apoptosis in human prostate cancer cells: Involvement of NQO1/xip3. Exp Cell Res 267: 95-106, 2001.

12. Müller K, Sellmer A and Wiegrebe W: Potential antipsoriatic agents: Lapacho compounds as potent inhibitors of HaCaT cell growth. J Nat Prod 62: 1134-1136, 1999.

13. Sitônio MM, Carvalho Júnior $\mathrm{CH}$, Campos IA, Silva JB Lima MC, Góes AJ, Maia MB, Rolim Neto PJ and Silva TG: Anti-inflammatory and anti-arthritic activities of 3,4-dihydro-2,2-dimethyl-2H-naphthol[1,2-b]pyran-5,6-dione ( $\beta$-lapachone). Inflamm Res 62: 107-113, 2013.

14. Frydman B, Marton LJ, Sun JS, Neder K, Witiak DT, Liu AA, Wang HM, Mao Y, Wu HY, Sanders MM, et al: Induction of DNA topoisomerase II-mediated DNA cleavage by beta-lapachone and related naphthoquinones. Cancer Res 57: 620-627, 1997.

15. Chau YP,Shiah SG, Don MJ and Kuo ML: Involvement of hydrogen peroxide in topoisomerase inhibitor beta-lapachone-induced apoptosis and differentiation in human leukemia cells. Free Radic Biol Med 24: 660-670, 1998.

16. Shiah SG, Chuang SE, Chau YP, Shen SC and Kuo ML: Activation of c-Jun NH2-terminal kinase and subsequent CPP32/Yama during topoisomerase inhibitor beta-lapachone-induced apoptosis through an oxidation-dependent pathway. Cancer Res 59: 391-398, 1999.

17. Choi YH, Kang HS and Yoo MA: Suppression of human prostate cancer cell growth by beta-lapachone via down-regulation of $\mathrm{pRB}$ phosphorylation and induction of Cdk inhibitor p21(WAF1/CIP1). J Biochem Mol Biol 36: 223-229, 2003.

18. Pink JJ, Wuerzberger-Davis S, Tagliarino C, Planchon SM, Yang X, Froelich CJ and Boothman DA: Activation of a cysteine protease in MCF-7 and T47D breast cancer cells during beta-lapachone-mediated apoptosis. Exp Cell Res 255: 144-155, 2000.

19. Wuerzberger SM,Pink JJ,Planchon SM,Byers KL,Bornmann WG and Boothman DA: Induction of apoptosis in MCF-7:WS8 breast cancer cells by beta-lapachone. Cancer Res 58: 1876-1885, 1998.

20. Dong GZ, Oh ET, Lee H, Park MT, Song CW and Park HJ: Beta-lapachone suppresses radiation-induced activation of nuclear factor-kappaB. Exp Mol Med 42: 327-334, 2010.

21. Yu HY, Kim SO, Jin CY, Kim GY, Kim WJ, Yoo YH and Choi YH: $\beta$-lapachone-induced apoptosis of human gastric carcinoma AGS cells is caspase-dependent and regulated by the PI3K/Akt pathway. Biomol Ther (Seoul) 22: 184-192, 2014.

22. Wierstra I: Sp1: Emerging roles - beyond constitutive activation of TATA-less housekeeping genes. Biochem Biophys Res Commun 372: 1-13, 2008.

23. Black AR, Black JD and Azizkhan-Clifford J: Sp1 and krüppel-like factor family of transcription factors in cell growth regulation and cancer. J Cell Physiol 188: 143-160, 2001

24. Kong LM, Liao CG, Fei F, Guo X, Xing JL and Chen ZN: Transcription factor $\mathrm{Sp1}$ regulates expression of cancer-associated molecule CD147 in human lung cancer. Cancer Sci 101: 1463-1470, 2010.

25. Sankpal UT, Goodison S, Abdelrahim M and Basha R: Targeting $\mathrm{Spl}$ transcription factors in prostate cancer therapy. Med Chem 7: 518-525, 2011.

26. Jiang Y, Wang L, Gong W, Wei D, Le X, Yao J, Ajani J, Abbruzzese JL, Huang S and Xie K: A high expression level of insulin-like growth factor I receptor is associated with increased expression of transcription factor Spl and regional lymph node metastasis of human gastric cancer. Clin Exp Metastasis 21: 755-764, 2004.

27. Kim DW, Ko SM, Jeon YJ, Noh YW, Choi NJ, Cho SD, Moon HS, Cho YS, Shin JC, Park SM, et al: Anti-proliferative effect of honokiol in oral squamous cancer through the regulation of specificity protein 1 . Int J Oncol 43: 1103-1110, 2013.

28. Zhang R, Luo H, Wang S, Chen W, Chen Z, Wang HW, Chen Y, Yang J, Zhang X, Wu W, et al: MicroRNA-377 inhibited proliferation and invasion of human glioblastoma cells by directly targeting specificity protein 1. Neuro Oncol 16: 1510-1522, 2014.

29. Abdelrahim M, Smith R III, Burghardt R and Safe S: Role of Sp proteins in regulation of vascular endothelial growth factor expression and proliferation of pancreatic cancer cells. Cancer Res 64: 6740-6749, 2004.

30. Shin JA, Han G, Kim HJ, Kim HM and Cho SD: Chemopreventive and chemotherapeutic effect of a novel histone deacetylase inhibitor, by specificity protein 1 in MDA-MB-231 human breast cancer cells. Eur J Cancer Prev 23: 277-285, 2014. 
31. Cho JH, Shin JC, Cho JJ, Choi YH, Shim JH and Chae JI: Esculetin (6,7-dihydroxycoumarin): A potential cancer chemopreventive agent through suppression of $\mathrm{Sp1}$ in oral squamous cancer cells. Int J Oncol 46: 265-271, 2015.

32. Safdie FM, Dorff T, Quinn D, Fontana L, Wei M, Lee C, Cohen P and Longo VD: Fasting and cancer treatment in humans: A case series report. Aging (Albany NY) 1: 988-1007, 2009.

33. Wilson RM and Danishefsky SJ: Small molecule natural products in the discovery of therapeutic agents: The synthesis connection. J Org Chem 71: 8329-8351, 2006.

34. Tobin DD, Menon M, Menon M, Spatta BC, Hodges EV and Perry DG: The intrapsychics of gender: A model of self-socialization. Psychol Rev 117: 601-622, 2010.

35. Li CJ, Averboukh L and Pardee AB: Beta-lapachone, a novel DNA topoisomerase I inhibitor with a mode of action different from camptothecin. J Biol Chem 268: 22463-22468, 1993.

36. Jackson JK, Higo T, Hunter WL and Burt HM: Topoisomerase inhibitors as anti-arthritic agents. Inflamm Res 57: 126-134, 2008.

37. Tudan C, Jackson JK, Higo TT and Burt HM: The effect of inhibiting topoisomerase I and II on the anti-apoptotic response associated with pro-inflammatory crystals of calcium pyrophosphate dihydrate in human neutrophils. Inflamm Res 52: 8-17, 2003 .

38. Safe $\mathrm{S}$ and Abdelrahim M: Sp transcription factor family and its role in cancer. Eur J Cancer 41: 2438-2448, 2005.

39. Li L and Davie JR: The role of Sp1 and $\mathrm{Sp} 3$ in normal and cancer cell biology. Ann Anat 192: 275-283, 2010.

40. Hsu TI, Wang MC, Chen SY, Yeh YM, Su WC, Chang WC and Hung JJ: Sp1 expression regulates lung tumor progression. Oncogene 31: 3973-3988, 2012.

41. Kavurma MM and Khachigian LM: Sp1 inhibits proliferation and induces apoptosis in vascular smooth muscle cells by repressing $\mathrm{p} 21^{\mathrm{WAF} 1 / \mathrm{Cipl}}$ transcription and cyclin D1-Cdk4-p21 ${ }^{\mathrm{WAF} 1 / \text { Cipl }}$ complex formation. J Biol Chem 278: 32537-32543, 2003.

42. Xu R, Zhang P, Huang J, Ge S, Lu J and Qian G: Sp1 and Sp3 regulate basal transcription of the survivin gene. Biochem Biophys Res Commun 356: 286-292, 2007.

43. Chae JI, Jeon YJ and Shim JH: Downregulation of Sp1 is involved in honokiol-induced cell cycle arrest and apoptosis in human malignant pleural mesothelioma cells. Oncol Rep 29: 2318-2324, 2013.

44. Hong IK, Byun HJ, Lee J, Jin YJ, Wang SJ, Jeoung DI, Kim YM and Lee $\mathrm{H}$ : The tetraspanin CD81 protein increases melanoma cell motility by up-regulating metalloproteinase MT1-MMP expression through the pro-oncogenic Akt-dependent Sp1 activation signaling pathways. J Biol Chem 289: 15691-15704, 2014.
45. Liu X, Yang WT and Zheng PS: Msi1 promotes tumor growth and cell proliferation by targeting cell cycle checkpoint proteins $\mathrm{p} 21$, p27 and p53 in cervical carcinomas. Oncotarget 5: 10870-10885, 2014.

46. Sherr CJ and Roberts JM: CDK inhibitors: Positive and negative regulators of G1-phase progression. Genes Dev 13: 1501-1512, 1999.

47. Murray AW: Recycling the cell cycle: Cyclins revisited. Cell 116: 221-234, 2004.

48. Ewen ME and Lamb J: The activities of cyclin D1 that drive tumorigenesis. Trends Mol Med 10: 158-162, 2004.

49. Weinstein IB: Relevance of cyclin D1 and other molecular markers to cancer chemoprevention. J Cell Biochem Suppl 25: 23-28, 1996.

50. Fu M, Wang C, Li Z, Sakamaki T and Pestell RG: Minireview: Cyclin D1: normal and abnormal functions. Endocrinology 145: 5439-5447, 2004.

51. Li F, Ambrosini G, Chu EY, Plescia J, Tognin S, Marchisio PC and Altieri DC: Control of apoptosis and mitotic spindle checkpoint by survivin. Nature 396: 580-584, 1998.

52. Jarrin M, Mansergh FC, Boulton ME, Gunhaga L and Wride MA: Survivin expression is associated with lens epithelial cell proliferation and fiber cell differentiation. Mol Vis 18: 2758-2769, 2012.

53. Xu Q, Liu M, Xu N and Zhu H: Variation in Sp1 binding sites correlates with expression of survivin in breast cancer. Mol Med Rep 10: 1395-1399, 2014.

54. Grütter MG: Caspases: Key players in programmed cell death. Curr Opin Struct Biol 10: 649-655, 2000.

55. Porter AG and Jänicke RU: Emerging roles of caspase-3 in apoptosis. Cell Death Differ 6: 99-104, 1999.

56. Elmore S: Apoptosis: A review of programmed cell death. Toxicol Pathol 35: 495-516, 2007.

57. Vaziri H, West MD, Allsopp RC, Davison TS, Wu YS, Arrowsmith CH, Poirier GG and Benchimol S: ATM-dependent telomere loss in aging human diploid fibroblasts and DNA damage lead to the post-translational activation of $\mathrm{p} 53$ protein involving poly(ADP-ribose) polymerase. EMBO J 16: 6018-6033, 1997.

58. Zauli G, Gibellini D, Caputo A, Bassini A, Negrini M, Monne M, Mazzoni $\mathrm{M}$ and Capitani S: The human immunodeficiency virus type-1 Tat protein upregulates Bcl-2 gene expression in Jurkat T-cell lines and primary peripheral blood mononuclear cells. Blood 86: 3823-3834, 1995 .

59. Yang E, Zha J, Jockel J, Boise LH, Thompson CB and Korsmeyer SJ: Bad, a heterodimeric partner for Bcl-XL and Bcl-2, displaces Bax and promotes cell death. Cell 80: 285-291, 1995. 